\title{
NITROGÊNIO, MOLIBDÊNIO E INOCULANTE PARA A CULTURA DO FEIJOEIRO1
}

\section{NITROGEN, MOLYBDENUM AND INOCULATE ON COMMON BEANS}

\author{
Sandra Mara VIEIRA ${ }^{2}$, \\ Pedro RONZELLI JÚNIOR ${ }^{3} \Xi^{\circ}$ \\ Edelclaiton DAROS ${ }^{4}$ \\ Henrique Soares KOEHLER ${ }^{5}$ \\ Beatriz Monte Serrat PREVEDELLO ${ }^{6}$
}

\begin{abstract}
RESUMO
Para avaliar os efeitos da aplicação isolada ou associada de nitrogênio, molibdênio e inoculante no rendimento de grãos da cultura do feijoeiro (Phaseolus vulgaris L.) e nos seus componentes principais, conduziram-se dois experimentos de campo num Latossolo Vermelho-amarelo álico, no ano agrícola de 1994/95, em Pinhais, PR. Utilizou-se, em ambos, o delineamento experimental de blocos ao acaso, com quatro repetições, com os tratamentos arranjados num fatorial $2^{3}$, ou seja, ausência e presença de nitrogênio, molibdênio e inoculante. O nitrogênio foi aplicado totalmente em cobertura na dosagem de $40 \mathrm{~kg} \mathrm{ha}^{-1}$ de $\mathrm{N}$, trinta dias após a emergência das plantas; nessa época também foi feita a aplicação do molibdênio, via foliar, na dosagem de $16,5 \mathrm{~g} \mathrm{ha}^{-1}$ de Mo. O inoculante foi aplicado às sementes nas proporções recomendadas pelo fabricante. Todos os tratamentos receberam adubação com $90 \mathrm{~kg} \mathrm{ha}^{-1}$ de $\mathrm{P}_{2} \mathrm{O}_{5}$ e $30 \mathrm{~kg} \mathrm{ha}^{-1}$ de $\mathrm{K}_{2} \mathrm{O}$ antes da semeadura. As variedades utilizadas foram 'Carioca' e 'IAPAR 31'. 'Verificou-se que entre as variedades foram encontrados resultados com diferenças estatisticamente significativas para a variedade 'IAPAR 31', que teve 0 rendimento influenciado significativa e positivamente pela interação de nitrogênio, molibdênio e inoculante, sendo o nitrogênio o mais eficiente dos integrantes da interação. O número de vagens por planta foi o componente do rendimento que evidenciou influência significativa e positiva pela presença de nitrogênio, não tendo sido observadas influências isoladas tanto de inoculante quanto de molibdênio.
\end{abstract}

Palavras-chave: Phaseolus vulgaris, nitrogênio, molibdênio, inoculante.

\begin{abstract}
The objective of this study was to evaluate, isolated or associated, of nitrogen $(\mathrm{N})$, molybdenum (Mo) and inoculate on common beans yield and its components effects. The experiments were carried out in the field, over an Oxisol, in Pinhais, PR, with two varieties of common beans ('Carioca' and 'IAPAR 31'), and two rates (with and without) respectively of N, Mo and inoculate, comprising a factorial, with four replications per treatment distributed on a complete randomized block experimental design. The inoculate was applied on the seeds following industry recommendations; $\mathrm{N}$ rate $(40 \mathrm{~kg}$ $\mathrm{ha}^{-1}$ ) was applied over the soil surface, in a single application, thirty days after emergence, and at this time Mo $\left(16,5 \mathrm{~g} \mathrm{ha}^{-1}\right)$ was sprayed on the plant leaves. All plots received $90 \mathrm{~kg} \mathrm{ha}^{-1}$ of $\mathrm{P}_{2} \mathrm{O}_{5}$ and $30 \mathrm{~kg}$ $\mathrm{ha}^{-1}$ of $\mathrm{K}_{2} \mathrm{O}$ plowed into the soil before seeding. Results with significant differences were found with 'IAPAR 31 ' variety that had the yield positively and significantly affected by the triple interaction ( $N$, Mo and inoculate) but $\mathrm{N}$ the greatest effect on it. The $\mathrm{N}$ also affected the number of pods per plant and were not seen any isolated influence Mo or inoculate.
\end{abstract}

Key-words: Phaseolus vulgaris, nitrogen, molybdenum, inoculate.

\footnotetext{
Parte da Dissertação de Mestrado da primeira autora, apresentada à Universidade Federal do Paraná (UFPR), para obtenção do grau de Mestre em Agronomia, área de concentração em Ciência do Solo.

Engenheira Agrônoma, M.Sc., Bolsista da CAPES.

3 Engenheiro Agrônomo, Doutor, Professor Adjunto IV, Departamento de Fitotecnia e Fitossanitarismo, UFPR, Caixa Postal 19061, CEP 81.531-990, Curitiba, PR, Bolsista do CNPq, E-mail: agroprj@agrarias.ufpr.br. $\equiv$ Autor para correspondência

4 Engenheiro Agrônomo, Doutor, Professor Adjunto IV, Departamento de Fitotecnia e Fitossanitarismo, UFPR.

5 Engenheiro Florestal, Mestre, Professor Adjunto IV, Departamento de Fitotecnia e Fitossanitarismo, UFPR.

6 Engenheira Agrônoma, Doutora, Professora Adjunta IV, Departamento de Solos, UFPR.
} 


\section{INTRODUÇÃO}

O Brasil é um dos maiores produtores e consumidores mundiais de feijão, porém com um rendimento médio de apenas $600 \mathrm{~kg} \mathrm{ha}^{-1}$ (5). Esse baixo rendimento ocorre em razão de processo inadequado de cultivo, condições climáticas adversas e incidência de pragas e doenças. Esses fatores aliados ao elevado custo dos fertilizantes concorrem para que a cultura seja considerada de subsistência pelos agricultores (2).

O nitrogênio é fator determinante na produtividade do feijoeiro (8). A resposta à utilização do nitrogênio tem sido generalizada em todo o Brasil, observando-se resposta positiva à aplicação desse nutriente (16). Estudos para reduzir o uso do nitrogênio na cultura, pelo processo de fixação simbiótica, têm sido realizados, porém, os resultados têm sido inconsistentes em função da influência de fatores fisiológicos e nutricionais (10). Entre os fatores nutricionais que interferem na fixação simbiótica do nitrogênio, destaca-se o papel desempenhado pelos micronutrientes, em particular o molibdênio. Apesar da pequena quantidade desse nutriente absorvida pela planta, o molibdênio é considerado essencial por fazer parte de duas enzimas, a redutase do nitrato e a nitrogenase (7). A redutase do nitrato promove a redução do nitrogênio absorvido na forma nítrica, para posteriormente ser incorporado em compostos orgânicos (13) e a nitrogenase catalisa a reação de fixação do nitrogênio atmosférico (18).

Testando a hipótese da substituição parcial ou total da adubação nitrogenada tradicional pela adubação foliar com molibdênio e/ou pelo uso de inoculante, decidiu-se conduzir experimentos a campo com o objetivo de verificar, para um solo álico, o efeito da aplicação isolada ou associada de nitrogênio, molibdênio e inoculante sobre o rendimento da cultura do feijoeiro e de seus componentes principais.

\section{METODOLOGIA}

Os experimentos foram conduzidos no ano agrícola de 1994/95, na Estação Experimental do Cangüiri, da Universidade Federal do Paraná (UFPR), localizada em Pinhais, PR. O solo é classificado como um Latossolo Vermelho Amarelo álico, A proeminente, textura argilosa, fase de campo subtropical e relevo suave ondulado (14), com as seguintes características químicas: $\mathrm{pH}_{(\mathrm{CaCl} 2)}=5,8 ; \mathrm{Ca}^{+2}=79 \mathrm{mmol}_{\mathrm{c}} \mathrm{kg}^{-1} ; \mathrm{Mg}^{+2}=47$ mmol kg-1; K=1,8 mmo $\mathrm{kg}^{-1} ; \mathrm{P}=18 \mathrm{mg} \mathrm{kg}^{-1}$ e $27 \mathrm{~g} \mathrm{~kg}^{-}$ ${ }^{1}$ de C. O clima da região é do tipo Cfb (subtropical úmido, mesotérmico), com verões frescos, geadas severas, sem estação seca, com temperatura média máxima de $24^{\circ} \mathrm{C}$ e mínima de $11^{\circ} \mathrm{C}$, precipitação média anual de $1.500 \mathrm{~mm}$ e umidade relativa do ar em torno de $30 \%(11)$.
O delineamento experimental utilizado foi o de blocos ao acaso com oito tratamentos, em arranjo fatorial $2^{3}$, e quatro repetições. As unidades experimentais eram canteiros com quatro linhas de $5,0 \mathrm{~m}$ de comprimento espaçadas, entre si, 0,5 m, perfazendo uma área total de $10,0 \mathrm{~m}^{2}$.

$\mathrm{O}$ nitrogênio foi aplicado em cobertura, na dosagem de $40 \mathrm{~kg} \cdot \mathrm{ha}^{-1}$ de $\mathrm{N}$, aos 30 dias após a emergência das plantas, utilizando-se como fonte a uréia. Nessa ocasião também aplicou-se o molibdênio, na forma de molibdato de sódio, via foliar, na dosagem de 16,5 g.ha-1 de Mo. O inoculante foi aplicado às sementes nas proporções recomendadas pelo fabricante. Todos os tratamentos receberam adubação com 90 kg.ha-1 de $\mathrm{P}_{2} \mathrm{O}_{5}$ e $30 \mathrm{~kg} \cdot$ ha $^{-1}$ de $\mathrm{K}_{2} \mathrm{O}$, utilizandose como fonte o superfosfato triplo e o cloreto de potássio, respectivamente, colocados no sulco de plantio antes da semeadura.

A cultura utilizada foi a do feijoeiro, variedades 'Carioca' e 'IAPAR 31', grãos tipo carioca, semeada na época das "águas". Foram colocadas 15 sementes por metro linear, obtendo-se população final de 240.000 plantas. ha ${ }^{-1}$, aproximadamente. Foram realizados os tratos culturais necessários para que a cultura se desenvolvesse normalmente.

A avaliação dos tratamentos foi feita por meio do rendimento da cultura, obtido pela colheita dos grãos (duas linhas centrais de cada parcela), números médios de vagens por planta e de sementes por vagem e massa média de 100 sementes. Os resultados foram submetidos à análise de variância. As variâncias foram avaliadas pelo teste de Barttlet e, quando consideradas homogêneas, avaliadas pelo Teste de F. As variáveis cujos resultados revelaram significância a $5 \%$ ou $1 \%$ de probabilidade tiveram as médias comparadas pelo teste de Tukey a $5 \%$ de probabilidade.

\section{RESULTADOS E DISCUSSÃO}

Os resultados das avaliações são apresentados nas Tabelas 1 e 2. Na Tabela 1, para a variedade 'Carioca', observa-se que não foram encontrados efeitos significativos de quaisquer dos tratamentos para as variáveis estudadas. Já na Tabela 2, para a variedade 'IAPAR 31', verifica-se que o rendimento foi influenciado significativa e positivamente pela interação de nitrogênio, molibdênio e inoculante. A causa dessa interação foi a presença do nitrogênio, uma vez que foi o único fator que mostrou efeito significativo quando isolado. $\mathrm{O}$ aumento no rendimento de grãos, devido ao nitrogênio, foi de $21 \%$, correspondendo a $280 \mathrm{~kg} \cdot \mathrm{ha}^{-1}$. Resultados semeIhantes foram obtidos, em condições diferentes, por outros pesquisadores $(1,6,9,15,17)$. A resposta ao nitrogênio, mesmo em condições de alto teor de 
TABELA 1 - Resultados de rendimento, em kg.ha-1 ${ }^{-1}$ número médio de vagens por planta (NMVP), número médio de sementes por vagem (NMSV) e massa média de 100 sementes (MM100S), da variedade de feijão comum 'Carioca', em condições de adubação com nitrogênio e molibdênio e infecção por inoculante. EEC/UFPR, Pinhais, PR, 1994/95

\begin{tabular}{|c|c|c|c|c|c|c|}
\hline \multicolumn{3}{|c|}{ Tratamentos ${ }^{1}$} & \multirow{2}{*}{$\begin{array}{l}\text { Rendimento } \\
\text { (kq.ha- }{ }^{-1} \text { ) }\end{array}$} & \multirow[t]{2}{*}{ NMVP } & \multirow[t]{2}{*}{ NMSV } & \multirow{2}{*}{$\begin{array}{c}\text { MM100S } \\
\text { (g) }\end{array}$} \\
\hline$\overline{\mathrm{N}}$ & Mo & $\overline{I N}$ & & & & \\
\hline 0 & - & - & 1304 & 13,9 & 4,5 & 22,1 \\
\hline 1 & - & - & 1224 & 13,6 & 4,5 & 21,4 \\
\hline- & 0 & - & 1264 & 13,7 & 4,4 & 21,5 \\
\hline - & 1 & - & 1262 & 13,7 & 4,5 & 22,0 \\
\hline - & - & 0 & 1336 & 13,8 & 4,5 & 22,2 \\
\hline - & - & 1 & 1192 & 13,7 & 4,5 & 21,3 \\
\hline 0 & 0 & - & 1268 & 13,7 & 4,5 & 21,6 \\
\hline 0 & 1 & - & 1340 & 14,1 & 4,5 & 22,5 \\
\hline 1 & 0 & - & 1262 & 13,8 & 4,4 & 21,4 \\
\hline 1 & 1 & - & 1186 & 13,4 & 4,6 & 21,5 \\
\hline 0 & - & 0 & 1440 & 13,9 & 4,5 & 22,4 \\
\hline 0 & - & 1 & 1168 & 13,9 & 4,5 & 21,8 \\
\hline 1 & - & 0 & 1232 & 13,7 & 4,5 & 22,0 \\
\hline 1 & - & 1 & 1214 & 13,5 & 4,5 & 20,9 \\
\hline - & 0 & 0 & 1354 & 13,8 & 4,4 & 21,9 \\
\hline - & 0 & 1 & 1176 & 13,6 & 4,5 & 21,0 \\
\hline - & 1 & 0 & 1318 & 13,7 & 4,6 & 22,4 \\
\hline - & 1 & 1 & 1208 & 13,8 & 4,5 & 21,7 \\
\hline 0 & 0 & 0 & 1462 & 13,5 & 4,4 & 21,9 \\
\hline 0 & 0 & 1 & 1076 & 13,9 & 4,5 & 21,3 \\
\hline 0 & 1 & 0 & 1418 & 14,2 & 4,5 & 22,8 \\
\hline 0 & 1 & 1 & 1262 & 13,9 & 4,5 & 22,2 \\
\hline 1 & 0 & 0 & 1246 & 14,2 & 4,4 & 22,0 \\
\hline 1 & 0 & 1 & 1276 & 13,4 & 4,4 & 20,7 \\
\hline 1 & 1 & 0 & 1218 & 13,2 & 4,6 & 22,0 \\
\hline 1 & 1 & 1 & 1152 & 13,7 & 4,6 & 21,1 \\
\hline
\end{tabular}

$\mathrm{N}=$ Nitrogênio $\quad \mathrm{Mo}=$ Molibdênio $\quad \mathrm{IN}=$ Inoculante $\quad 0=$ Ausência $\quad 1=$ Presença

TABELA 2 - Resultados de rendimento, em kg.ha-1, número médio de vagens por planta (NMVP), número médio de sementes por vagem (NMSV) e massa média de 100 sementes (MM100S), em g, da variedade de feijão comum 'IAPAR 31', em condições de adubação com nitrogênio e molibdênio e infecção por inoculante. EEC/UFPR, Pinhais, PR, 1994/951

\begin{tabular}{|c|c|c|c|c|c|c|}
\hline \multicolumn{3}{|c|}{ Tratamentos $^{2}$} & \multirow{2}{*}{$\begin{array}{l}\text { Rendimento } \\
\left(\mathrm{kg} \cdot \mathrm{ha}^{-1}\right)\end{array}$} & \multirow[t]{2}{*}{ NMVP } & \multirow[t]{2}{*}{ NMSV } & \multirow{2}{*}{$\begin{array}{c}\text { MM100S } \\
\text { (g) }\end{array}$} \\
\hline$\overline{\mathrm{N}}$ & Mo & IN & & & & \\
\hline 0 & - & - & $1327 b$ & $11,9 b$ & 4,9 & 20,6 \\
\hline 1 & _- & - & $1607 \mathrm{a}$ & $14.1 \mathrm{a}$ & 48 & 20.3 \\
\hline - & 0 & - & 1457 & 12,4 & 4,8 & 20,2 \\
\hline - & 1 & - & 1477 & 13,6 & 4,9 & 20,7 \\
\hline - & - & 0 & 1408 & 12,6 & 4,8 & 20,2 \\
\hline - & - & 1 & 1526 & 13,4 & 4,9 & 20,7 \\
\hline 0 & 0 & - & 1331 & 11,4 & 4,9 & 20,5 \\
\hline 0 & 1 & - & 1323 & 12,3 & 4,9 & 20,7 \\
\hline 1 & 0 & - & 1583 & 13,4 & 4,8 & 19,9 \\
\hline 1 & 1 & - & 1631 & 14,9 & 4,9 & 20,7 \\
\hline 0 & - & 0 & 1206 & 11,3 & 4,9 & 20,1 \\
\hline 0 & - & 1 & 1448 & 12,4 & 4,9 & 21,1 \\
\hline 1 & - & 0 & 1610 & 14,0 & 4,8 & 20,3 \\
\hline 1 & - & 1 & 1604 & 14,3 & 4,9 & 20,3 \\
\hline- & 0 & 0 & 1376 & 11.6 & 4.8 & 19.6 \\
\hline - & 0 & 1 & 1538 & 13,2 & 4,8 & 20,8 \\
\hline - & 1 & 0 & 1438 & 13,7 & 4,8 & 20,8 \\
\hline - & 1 & 1 & 1516 & 13,6 & 5,0 & 20,5 \\
\hline 0 & 0 & 0 & $1098 \mathrm{~b}$ & 10,1 & 4,8 & 19,8 \\
\hline 0 & 0 & 1 & $1564 \mathrm{ab}$ & 12,7 & 4,9 & 21,2 \\
\hline 0 & 1 & 0 & $1314 a b$ & 12,5 & 4,9 & 20,5 \\
\hline 0 & 1 & 1 & $1332 a b$ & 12,2 & 4,9 & 21,0 \\
\hline 1 & 0 & 0 & $1656 \mathrm{ab}$ & 13,1 & 4,8 & 19,3 \\
\hline 1 & 0 & 1 & $1510 a b$ & 13,6 & 4,7 & 20,5 \\
\hline 1 & 1 & 0 & $1564 a b$ & 14,9 & 4,7 & 21,2 \\
\hline 1 & 1 & 1 & $1698 a$ & 15,0 & 5,1 & 20,5 \\
\hline
\end{tabular}

Médias seguidas de mesma letra não diferem significativamente pelo teste de Tukey a $5 \%$ de probabilidade.

$\mathrm{N}=$ Nitrogênio $\quad \mathrm{Mo}=$ Molibdênio $\quad \mathrm{IN}=$ Inoculante $\quad 0=$ Ausência $\quad 1=$ Presença 
matéria orgânica do solo (>2,5\%), indica que nem sempre o nitrogênio dessa fonte está disponível. Também o fato de o $\mathrm{pH}$ estar próximo da neutralidade (5,8 em $\left.\mathrm{CaCl}_{2}\right)$ pode ter contribuído para aumentar a disponibilidade de molibdênio no solo e diminuído os efeitos do tratamento com a aplicação desse micronutriente.

Pode-se ver, também pela Tabela 2, que o número médio de vagens por planta foi o componente do rendimento que melhor representou o rendimento, tendo sido influenciado significativa e positivamente pelo nitrogênio com $18,5 \%$ a mais que a testemunha, resultado já observado (4) e contes-tado (3).

Os componentes do rendimento, número de sementes por vagem e peso de 100 sementes (Tabela 1) não foram influenciados significativamente pelos tratamentos. A variedade 'IAPAR 31' apresentou um número médio de sementes por vagem de 4,9 e peso médio de 100 sementes de
$20,5 \mathrm{~g}$, valores que podem ser considerados normais para esta variedade (12).

\section{CONCLUSÕES}

1) Entre as variedades foram observadas diferenças estatisticamente significativas nos resultados das variáveis analisadas para 'IAPAR 31'.

2) O rendimento de grãos foi influenciado positivamente pela interação de nitrogênio, molibdênio e inoculante para a variedade 'IAPAR 31'.

3) As diferenças encontradas são atribuídas à presença do adubo nitrogenado.

4) O número de vagens por planta foi o componente do rendimento influenciado positivamente pelo nitrogênio aplicado.

5) Não foi observada influência tanto do inoculante quanto do molibdênio, em quaisquer das variáveis analisadas.

\section{REFERÊNCIAS}

1 ALMEIDA, L.D.; PESSANHA, G.G.; PENTEADO, A.F. Efeito da calagem e da adubação fosfatada e nitrogenada na nodulação e produção do feijoeiro (Phaseolus vulgaris L.). Pesquisa Agropecuária Brasileira, Brasília, v.8, p.127-130, 1973.

2 ARAÚJO, G.A.A.; FONTES, L.A.N.; AMARAL, F.A.L.; CONDÉ, A.R. Influência do molibdênio e do nitrogênio sobre duas variedades de feijão (Phaseolus vulgaris L.). Ceres, Viçosa, v.34, p.333-339, 1987.

3 ARF, O.; FORNASIERI FILHO, D.; MALHEIROS, E.B.; SAITO, S.M.T. Efeito da inoculação e adubação nitrogenada em feijoeiro (Phaseolus vulgaris L.) Cultivar Carioca 80. I. Solo de alta fertilidade. Científica, São Paulo, v.19, p.29-38, 1991.

4. BENNET, J.P.; ADAMS, M.W.; BURGA, C. Pod yield component variation and intercorrelation in Phaseolus vulgaris L. as affected by planting density. Crop Science. Madison, v.17, p.73-75, 1977.

5 CEPA. Síntese anual da agricultura catarinense. Florianópolis: Instituto CEPA/SC, 1994.

6 CHAGAS, J.M.; VIEIRA, C. Efeitos de intervalos de plantio e de níveis de adubação sobre o rendimento e seus componentes, em algumas variedades de feijão (Phaseolus vulgaris L.). Ceres. Viçosa, v.22, p.244-263, 1975.

7 DECHEN, A. R.; HAAG, H.P.; CARMELLO, Q.A.C. Mecanismos de absorção e de translocação de micronutrientes. In: FERREIRA, M. E. Micronutrientes na agricultura. Piracicaba: Associação Brasileira para Pesquisa da Potassa e do Fosfato, 1991. p.79-111.

8 FONTES, L.A.N.; BRAGA, L.J.; GOMES, F.R. Resposta da cultura do feijão (Phaseolus vulgaris L.) à aplicação do calcário e do adubo nitrogenado e fosfatado em municípios da Zona da Mata, Minas Gerais. Ceres, Viçosa, v.20, p.313-325, 1973.

9 FORNASIERI FILHO, D.; BELLINDIERI, P.A.; VITTI, G.C.; MALHEIROS, E.B.; HORIENTE, E.C. Efeitos da inoculação com Rhizobium phaseoli de fertilizantes às sementes e nitrogênio mineral na cultura do feijoeiro (Phaseolus vulgaris L.) Carioca das "águas". Científica, São Paulo, v.16, p.229-238, 1988.

10 FRANCO, A.A.; DÖBEREINER, J. Fixação biológica do nitrogênio. Brasília, 1988. (Curso de Agricultura Tropical. Módulo 2: Os Solos Tropicais. EMBRAPA).

11 IAPAR - Instituto Agronômico do Paraná. Cartas climáticas básicas do Estado do Paraná. Londrina: IAPAR, 1994, 45p.

12 IAPAR - Instituto Agronômico do Paraná. O feijão no Paraná. Londrina: IAPAR, 1989, 303p. (Circular 63).

13 MENGUEL, K.; KIRBY, E.A. Principles of plant nutrition. 4. Ed. Bern, International Potash Institute, 1987.

14 OLMOS-I. L.J.; CARDOSO, A.; CARVALHO, A.P.; HOCHMÜLER, D.P.; FASOLO, P.J.; RAÜEN, M.J. Levantamento de reconhecimento dos solos do Estado do Paraná. Londrina: EMBRAPA/SNLCS/SUDESUL/IAPAR, 1984. v.2, p. 451-791 (Boletim Técnico, 57 EMBRAPA, 16 IAPAR).

15 RONZELLI JÚNIOR, P.; FEITOSA, C.T.; ALMEIDA, L.D’A. Formulações comerciais e PK na presença de nitrogênio em cobertura e/ou adubação foliar para feijoeiro. Campinas: Instituto Agronômico, 1984, 10p. (Boletim Técnico 90).

16 ROSOLEM, C.A. Nutrição e adubação do feijoeiro. Piracicaba: Associação Brasileira para Pesquisa da Potassa e do Fosfato, 1987, 93p. (Boletim Técnico 8).

17 SANTA CECÍLIA, F.C.; RAMALHO, M.A.P.; SILVA, C C. Efeitos da adubação NPK na cultura do feijão (Phaseolus vulgaris L.) na Zona Sul de Minas Gerais. Agros, Lavras, v.4, p.3-10, 1974.

18 TANAKA, R.T.; MASCARENHAS, H.A.A.; BULISANI, E.A.; CAMPIDELLI, C.; DIAS, O.S. Resposta da soja ao molibdênio aplicado em solo arenoso de cerrado de baixa fertilidade. Pesquisa Agropecuária Brasileira, Brasília, v.28, p.253-256, 1993. 